\title{
The best available technology for small electroplating plants applying analytical hierarchy process
}

\author{
${ }^{1 *}$ M. R. Dabaghian; ${ }^{2}$ S. H. Hashemi; ${ }^{1}$ T. Ebadi; ${ }^{1}$ R. Maknoon \\ ${ }^{1}$ Department of Civil and Environmental Engineering, Amirkabir University of Technology, Tehran, Iran \\ ${ }^{2}$ Environmental Science Research Institute, Shahid Beheshti University, Tehran, Iran \\ Received 10 April 2008; $\quad$ revised 15 June 2008; accepted 15 July 2008; available online 1 September 2008
}

\begin{abstract}
In this study analytical hierarchy process approach which uses expert's knowledge, was applied for selection of the best wastewater treatment alternative for electroplating workshops, located in Tehran province, Iran. This method can be applied for complicated multi-criteria decision making to obtain scientific and reasonable results. Four wastewater treatment alternatives including reverse osmosis, nano filtration, ion exchange, and chemical precipitation were evaluated and ranked based on economical, technical, environmental/ social aspects. Each criterion includes different indices such as land area, capital cost, sludge disposal issues, operating and maintenance, local suppliers and warranty, system flexibility, required skilled and non skilled man power safety, and etc. The results showed that reverse osmosis achieved the maximum general profits and can be the best choice. Sensitivity analysis can shows the effect of inputs parameters change on the results. Sensitivity analysis was applied for each criterion. The results illustrated that for economic and technical criterion, chemical precipitation and for environment criterion, reverse osmosis were qualified.
\end{abstract}

Key words: Heavy metals, reverse osmosis, nano filtration, ion exchange, chemical precipitation

\section{INTRODUCTION}

There is a specific emphasizes on public awareness about water pollution issues in environmental law and regulations. This is a driving force for constructing new wastewater treatment plants (Guangming et al., 2007; Handfield et al., 2001). One of the most important and earlier subjects is selecting the best wastewater treatment alternative, before detail designing and constructing the plant. Normally, in some of the developing countries wastewater treatment alternatives are evaluated only based on economic criterion (Guangming et al., 2007).

A number of studies and optimization models have been developed for finding the best wastewater treatment alternative during past years (Evenson et al., 1969). However, most of them just considered capital and operation costs (Rossman, 1980; USEPA, 1975, 1993 and 2002). But in fact, the minimum cost alternative may not be necessarily the best choice (Tsagarakis et al., 2001 and 2003; Qasim, 1998).

The bes $t$ treatment process may be the one associated with minimum capital cost, minimum pollutant discharge and maximum environmental/ social ه*Corresponding Author Email: r_dabaghyan@yahoo.com Tel./Fax: +9821 22324650 benefits (Ellis and Tang, 1991 and 1994; Gupta, 1995). In this case, many criteria such as land area and cost, capital cost, power consumption, and environmental/ social impacts, may be considered for the decision making process. These factors can be considered in three criteria: economical, technical and environmental/ social. However the interrelationship between them is so complicated and usually one criterion affect on the others. Thus it is not easy to model and find the best solution by using the independent criteria (Keeny and Raiffa, 1993; Beynon et al., 2000; Handfield et al., 2001; Peniwati, 2007).

The analytical hierarchy process, is an adopted method to handle multiple criteria and objectives in decision-making (Saaty, 1977). AHP can be applied for environmental / social objectives which are recognized to be as the same important as the economic objective in selecting the best wastewater treatment alternative (Guangming et al., 2007). This approach can evaluate different objectives and can characterize the differences between two alternatives by priority vector (Huang et al., 1996; Tsiporkova and Boeva, 2006; Davis, 1996). However, it depends on the subjective weight of each 
parameter that can be obtained by experience (CheWei et al., 2007; Arieh, 2005).

In this paper, experts' knowledge was integrated by weighing criteria and indices. The best wastewater treatment alternative was selected by AHP. The study was focused on Tehran province electroplating plants and has been done during 2007 year.

\section{MATERIALS AND METHODS}

The AHP is a systematic technique for multi-criteria decision-making that facilitates an abstruse definition of premiership and precedence of decision makers (Saaty, 1980). It is assumed there are $n$ criteria in the process that the relative priority of each is defined against the others. This problem can be set as a hierarchy and a pair wise comparison which have been done between each pair of criteria at their level of the hierarchy. Normally, as it shows in Table 1, the comparison result ranks 1 to 9 . These pair wise comparison yield a reciprocal n-by-n matrix, where $a_{i i}=1$ and $a_{j i}=1 / a_{i j}$.

The first column of matrix $A$ shows the relative importance of criterion $2,3, \ldots, n$ with respect to criterion 1. Therefore, the comparison for each column and each pair needs an independent judgment. Thus, matrix $A$ shows the relative weights and matrix $w$ shows the vector of weights $w=\left(w_{1}, w_{2}, \ldots, w_{n}\right)$ yields:

$$
A w=\left[\begin{array}{cccc}
a_{11} & a_{12} & \ldots & a_{1 n} \\
a_{21} & a_{22} & \ldots & a_{2 n} \\
\vdots & \vdots & & \vdots \\
a_{n 1} & a_{n 2} & \ldots & a_{n n}
\end{array}\right]\left[\begin{array}{c}
w_{1} \\
w_{2} \\
\vdots \\
w_{n}
\end{array}\right]=n\left[\begin{array}{c}
w_{1} \\
w_{2} \\
\vdots \\
w_{n}
\end{array}\right]
$$

Therefore, to recover matrix of ratios, the problem $A w$ $n w=0$ representing a homogenous linear equations, must be solved. This system has a nontrivial solution if and only if the determinant of (A-nI) vanishes; meaning that $n$ is an eigenvalue of $A$. Obviously $A$ has unit rank since every row is a constant multiple of the first row and thus all eigenvalues except one are zero. The sum of the eigenvalues of a matrix equals its trace and in this case, the trace of $A$ equals $n$. Thus $n$ is an eigenvalue of $A$ and a nontrivial solution. Generally, a consistency ratio (CR) value of $10 \%$ or less is considered as acceptable, otherwise the pair wise comparisons should be revised (Saaty, 1990).

Thus, the resulting weighting vector for a criterion level with respect to the overall objective can be denoted as:

$W_{C}=\left(w_{C 1}, \ldots, w_{C k}, \ldots, w_{C S}\right)$

Where $w_{C k}(k=1,2, \ldots, s)$ is the weight of the $k^{\text {th }}$ criterion $C_{k}$ with respect to the overall objective. Similarly, the weighting vector for the each index level with respect to the $k^{\text {th }}$ criterion $C_{k}$ can be denoted as:

$W_{C k}=\left(w_{I_{p}}, w_{I_{p+1}}, \ldots, w_{I_{q}}\right)$

Where $I_{p}, I_{p+1}, \ldots, I_{q}(1 d$ "pd"qd" $n)$ are the index subject to the $k^{\text {th }}$ criterion $C_{k} ; p$ and $q$ are serial numbers of the first and the last index subject to the $k^{\text {th }}$ criterion $C_{k}$. If there are $l$ index subject to the $k^{\text {th }}$ criterion $C_{k}$, then $q=p+1$. (Vargas, 1982).

Three economical, technical and environmental/ social criteria considered in the hierarchy system for selecting wastewater treatment alternative. For each criterion introduced a few indices that quantified and normalized to produce comparable data. Quantitative indices such as land area and capital cost were obtained by using experts' judgment. However, there were some qualitative indices such as system flexibility, required skilled man power, heavy metals removal efficiency, and environmental/ social impacts. These indices are classified to nine grades by descriptive language including very important [9], important [7], moderate [5], low [3] and very low [1] and four intermediate grades (Saaty, 1980; Cheng and Wang, 2004; Dryden, 2005).

Economic, environmental/ social and technical performances data for each treatment alternative

Table1: The comparison result and related rank

\begin{tabular}{ll}
\hline Rank & \multicolumn{1}{c}{ Comparative importance definition explanation } \\
\cline { 2 - 3 } 1 & Equally important Two decision criteria equally influence the parent decision criterion. \\
3 & Moderately more important one decision criterion is moderately more influential than the other. \\
5 & Strongly more important one decision criterion has stronger influence than the other. \\
7 & Very strongly more important one decision criterion has significantly more influence over the other. \\
9 & Extremely more important the difference between influences of the two decision criteria is extremely significant. \\
$2,4,6,8$ & Intermediate judgment values Judgment values between equally, moderately, strongly, very strongly, and extremely. \\
\hline Source: Saaty (1977)
\end{tabular}


obtained through experts judgment by filling the questionnaire. For example, the "very important" grade denotes that the technology which produces low quantity sludge is more preferable than the others (Millet and Saaty, 2000; Huynh and Nakamori, 2005; Cheng and Wang, 2004).

Before normalization, in index level, each index shall be averaged. If there are $n$ people who answered the questionnaire and $m$ is the grade that each one selected, weight of each index obtains as below:

$w=\frac{\sum_{i=1}^{n} i m_{i}}{n} \quad(i=1,2, \ldots, n)$

Equations with various units shall be transformed to the same numeric order. In this study, linear normalization is utilized to transfer index data to the range between zero and one (Mendenhall et al., 1986).

\section{RESULTS AND DISCUSSION}

Since the flow rate of most of electroplating plants in Tehran is less and about $5 \mathrm{~m}^{3} / \mathrm{d}$; in this study two flow rates of $1 \mathrm{~m}^{3} / \mathrm{d}$ and $5 \mathrm{~m}^{3} / \mathrm{d}$ were used as the designing flow rate.

Four treatment alternatives include reverse osmosis, nano filtration, ion exchange and chemical precipitation are studied. Table 2 shows the objective hierarchy for the selected treatment alternative. Fig. 1 shows the hierarchy decision model which has four levels. First level is goal that shows the best electroplating wastewater treatment alternative which has the maximum general profits. Three main criteria: economic, technical and environmental/ social are located in the second level. Indices of each main criterion are in the third level, and the last level is treatment alternatives.

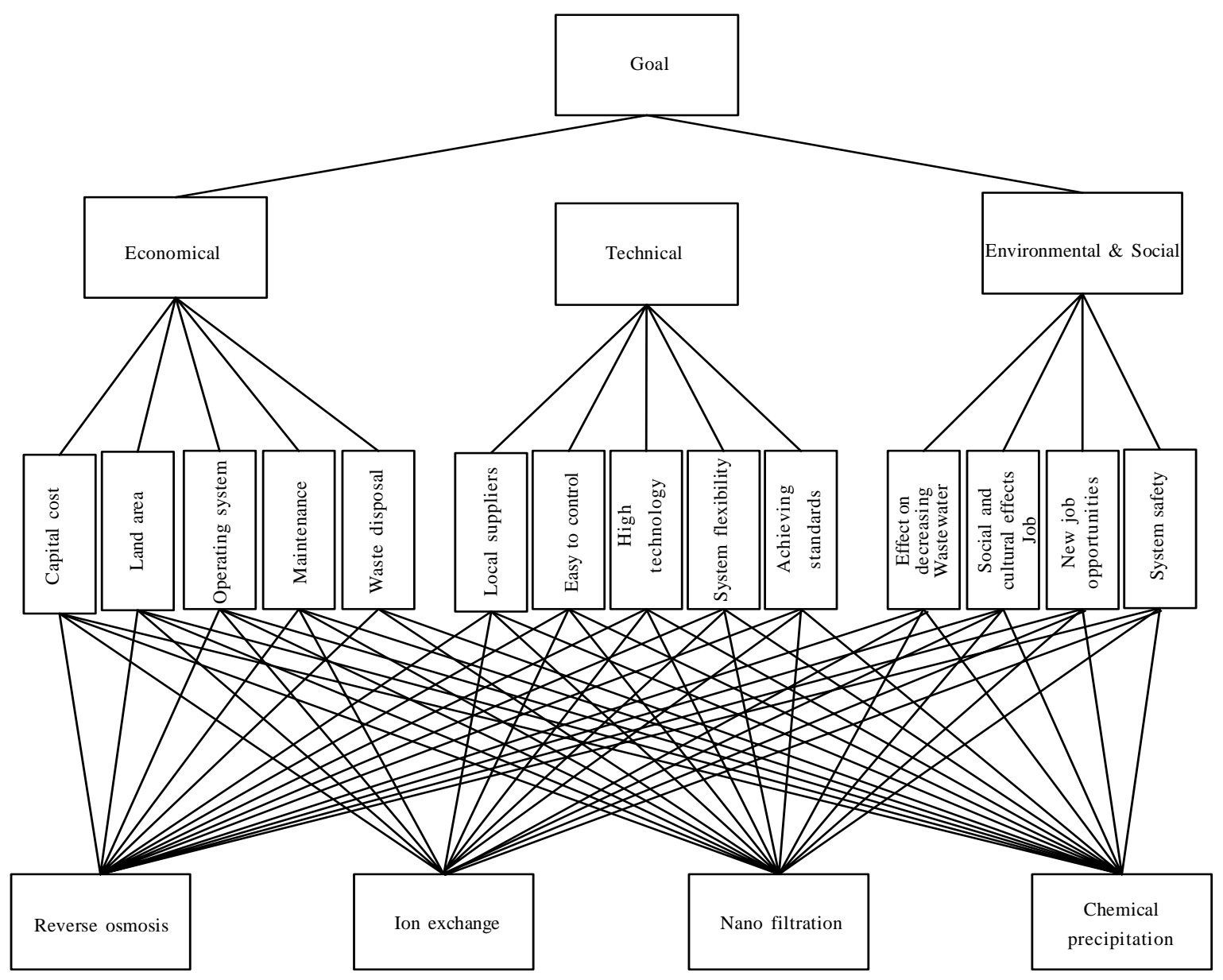

Fig. 1: Analytical hierarchy decision model used in this study 
Available technology for small electroplating plants

Table2: Objective hierarchy for the selected treatment alternative

\begin{tabular}{llll}
\hline Criteria & Criteria weight & Index & Index weight \\
\hline & & land area (I1) & 0.202 \\
Economical & 0.361 & capital cost (I2) & 0.209 \\
& & operating system (I3) & 0.201 \\
& maintenance (I4) & 0.199 \\
& & waste disposal (I5) & 0.189 \\
& & using national facilities (I6) & 0.218 \\
Technical & & easy to control (I7) & 0.217 \\
& 0.313 & high technology (I8) & 0.186 \\
& & flexibility (I9) & 0.158 \\
& & meeting standards (I10) & 0.220 \\
Environmental/social & 0.326 & reducing wastewater (I11) & 0.302 \\
& & social and cultural effects (I12) & 0.240 \\
& & required man power (I13) & 0.209 \\
\end{tabular}

Table 3: Weights of criteria and indices

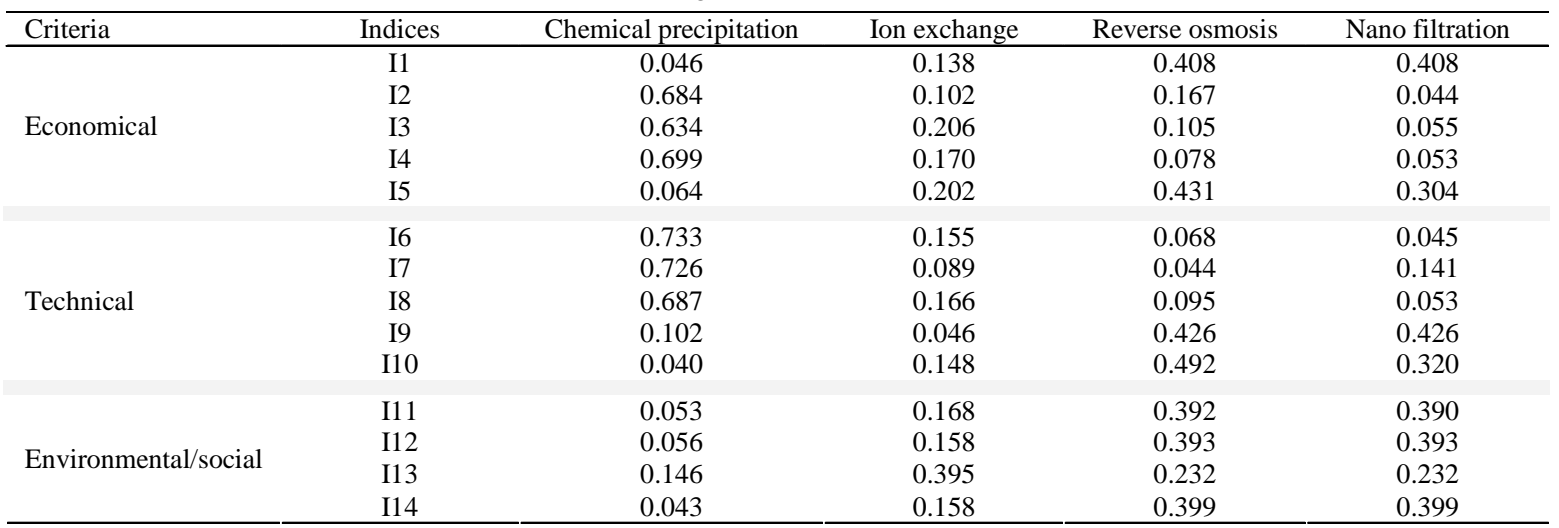

After developing the hierarchy model, three main criteria and their indices were evaluated by experts including engineers, academics and electroplating owners using a questionnaire. Fig. 2 and Table 3 show the effective weights of criteria and indices for each group and the linear average of the all questionnaires, respectively. Then the expert choice program was used to calculate the consistency ratio value (CR) of $2 \%$ (which is $<10 \%$ ). The weight of economic criterion obtained 0.361 which showed it was the most important criterion in experts' vision, but its priority was not dominant against the two other criteria. It can be explained by experts' attitude. Due to the significance of heavy metals removal from electroplating wastewater, the weight of two other criteria increased. As a result of the limited land area and its high price in the study area, the capital cost and land area were the most important indices in economic criterion.
The results showed the best alternative for $1 \mathrm{~m}^{3} / \mathrm{d}$ and $5 \mathrm{~m}^{3} / \mathrm{d}$ flow rates were chemical precipitation and reverse osmosis with 0.33 and 0.31 scores, respectively. Sensitivity analysis can shows the effect of inputs parameters change on the results. The sensitivity analysis for criteria level showed the economic criterion is the most important parameter for technology selection and when its weight reached to 0.43 , chemical precipitation will be the best technology for both $1 \mathrm{~m}^{3 /}$ $\mathrm{d}$ and $5 \mathrm{~m}^{3} / \mathrm{d}$ flow rates. In view of technical criterion when its weight reached 0.47 , again the best technology will be chemical precipitation. Considering environmental/ social criterion, nano filtration and reverse osmosis are the best technologies for both flow rates in all conditions. When the weights of economic and technical criteria reduced, the best technology was reverse osmosis for both flow rates. Also, this technology was the first choice when all criteria were considered. 


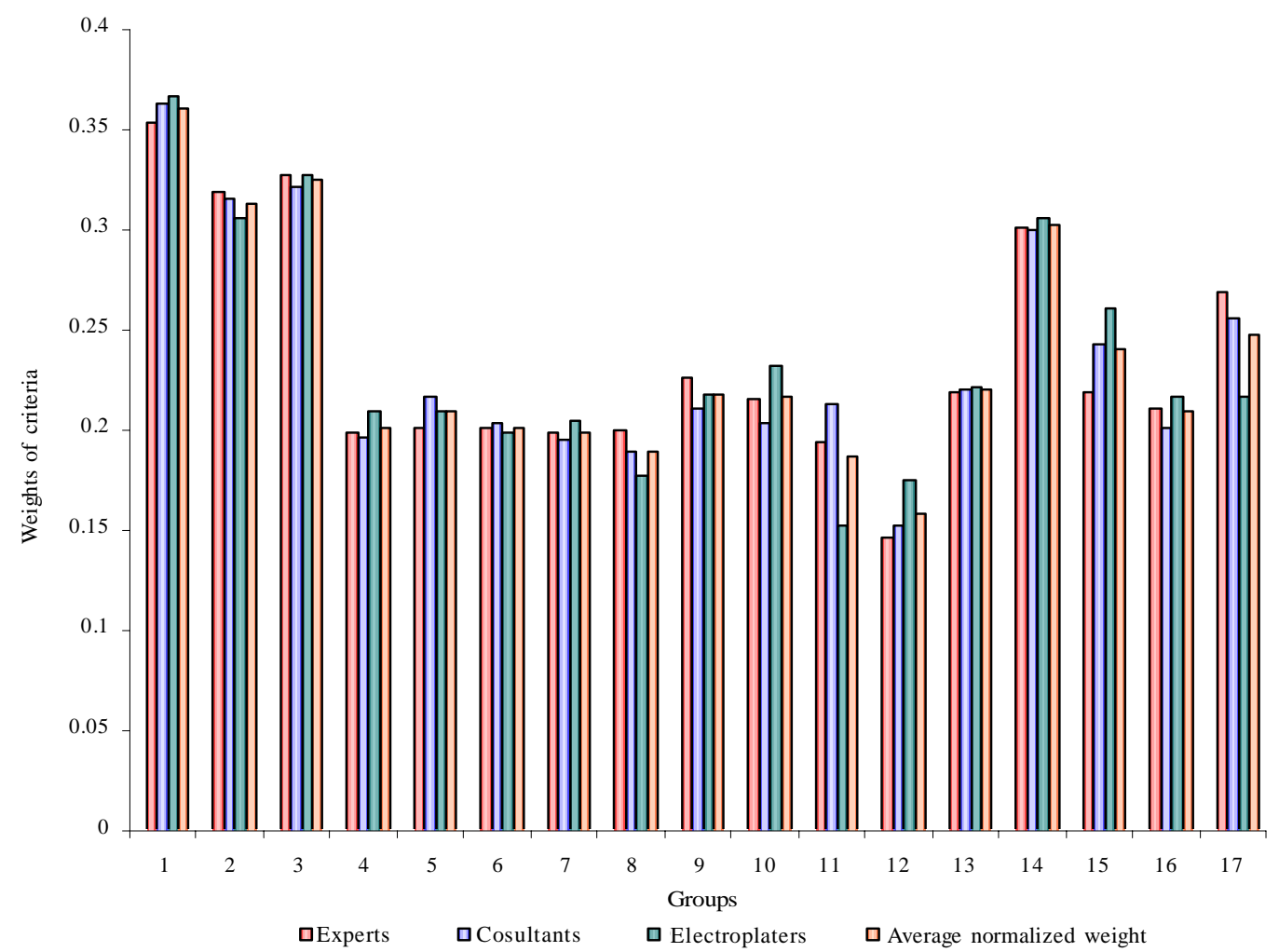

Fig. 2: Normalized weights of criteria and indices for each evaluator group

AHP model allows more effective reflection of the actual characteristics of the problem compare to the mono level based evaluation. As the weights of each index are different, significance level of each index is different. Hence, subjectivity and randomness have been avoided. Besides, the quantified scale evaluating by experts, makes the selection of wastewater treatment alternative more comparable and comprehensive.

\section{REFERENCES}

Arieh, D. B., (2005). Sensitivity of multi-criteria decision making to linguistic quantifiers and aggregation means. Comput. Ind. Eng., 48, 289-309.

Beynon, M. J.; Curry, B.; Morgan, P. H., (2000). The dempstershafer theory of evidence: An alternative approach to multi criteria decision modeling. Omega. 28 (1), 37-50.

Che-Wei, C.; Cheng-Ru, W.; Chin-Tsai, L.; Huang-Chu, C., (2007). An application of AHP and sensitivity analysis for selecting the best slicing machine. Comput. Ind. Eng., 52 (2), 296-307.

Cheng, S.; Wang, R., (2004). Analyzing hazard potential of typhoon damage by applying grey analytic hierarchy process. Nat. Hazards, 33 (1), 77-103.

Davis, D. H., (1996). Group decision making and quantitative judgments: a consensus model, in: E. Witte, J.H. Davis (Eds.), Understanding group behaviour consensual action by small groups, Vol. 1, Lawrence Erlbaum, Mahwah, NJ, 35-59.

Dryden, J. B., (2005), A decision model to optimize the hydrologic cycle of high performance buildings in Florida. PhD Thesis, Florida University.

Ellis, K. V.; Tang, S. L., (1991). Wastewater treatment optimization model for developing world. I: Model development. J. Environ. Eng-ASCE, 117 (4), 501-581.

Ellis, K. V.; Tang, S. L., (1994). Wastewater treatment optimization model for development world. II: Model testing. J. Environ. Eng-ASCE, 120 (3), 610-624.

Evenson, D. E.; Orlob, G. T.; Monser, J. R., (1969). Preliminary selection of waste treatment systems. J. Water Pollut. Cont. F., 41 (11), 1845-1858.

Guangming, Z.; Ru, J.; Guohe, H.; Min, X.; Jianbing, L., (2007). Optimization of wastewater treatment alternative selection by hierarchy grey relational analysis. J. Environ. Manage. 82 (2) 250-259.

Gupta, M. C., (1995). Environmental management and its impact on the operations function. Int. J. Oper. Prod. Manage., 15 (8), 34-51.

Handfield, R.; Steven, V.; Walton, R. S.; Steven, A. M., (2002). Applying environmental criteria to supplier assessment: A study in the application of the Analytical hierarchy process. Eur. J. Oper. Res. 141 (1), 70-87.

Huang, G. H.; Baetz, B. W.; Patry, G. G., (1996). A grey hop, skip and jump approach: generating alternatives for expansion planning of waste management facilities. J. Civil Eng., 23, 1207-1219. 
Huynh, V. A.; Nakamori, Y., (2005). A satisfactory-oriented approach to multi-expert decision-making with linguistic assessments, IEEE Trans. Systems Man Cybernet. Part B., 35, 184-196.

Keeny, R. L.; Raiffa, H., (1993). Decision making with multiple objectives: Preferences and value tradeoffs. Cambridge University Press, Cambridge, UK.

Mendenhall, W.; Beaver, R.; Reinmuth, J. E., (1986). Statistics for management and economics. PWS-Kent Pub Co.

Millet, I., Saaty, T. L., (2000). On the relativity of relative measures-accommodating both rank preservation and rank reversals in the AHP. Eur. J. Oper. Res., 121 (1), 205-12.

Peniwati, K., (2007). Criteria for evaluating group decisionmaking methods. Math. Comput. Model., 46 (7-8) 935947.

Qasim, S. R., (1998). Wastewater treatment plants: Planning, design, and operation, $2^{\text {nd. }}$ Ed. University of Texas, Arlington, USA, CRC Press.

Rossman, L. A., (1980). Synthesis of waste treatment systems by implicit enumeration. J. Water Pollut. Control F., 52 (1), 147-160.

Saaty, T. L., (1977). A scaling method for priorities in hierarchical structures. J. Math. Psychol., 15 (3), 234-281. Saaty, T. L., (1980). The analytical hierarchy process. McGraw-Hill, New York.
Saaty, T. L. (1990). How to mark a decision: the analytic hierarchy process. Eur. J. Oper. Res., 48 (1), 9-26.

Tsagarakis, K. P.; Mara, D. D.; Angelakis, A. N., (2003). Application of cost criteria for selection of municipal wastewater treatment systems, Water Air Soil Pollut., 142 (1-4), 187- 210

Tsagarakis, K. P.; Mara, D. D.; Horn, N. J.; Angelakis, A. N., (2001). Institutional status and structure of wastewater quality management in Greece, Water Policy, 3 (1), 81- 99.

Tsiporkova, E.; Boeva, V., (2006). Multi-step ranking of alternatives in a multi-criteria and multi-expert decision making environment. Inform. Science. 176 (12): 2673-2697.

USEPA, (1975). Guide to the selection of cost-effective wastewater treatment systems.

USEPA, (1993). Development document for the proposed effluent limitation guidelines and standards. EPA, Office of Water, EPA-821-R-93-019.

USEPA, (2002). Development document for the proposed effluent limitation guidelines and standards. EPA, Office of Water, EPA-821-B-01-007.

Vargas, L. G., (1982). Reciprocal matrices with random coefficients, J. Math. Model., 3 (1), 69-81.

\section{AUTHOR (S) BIOSKETCHES}

Dabaghian, M. R., M.Sc. student, Department of Civil and Environmental Engineering, Amirkabir University of Technology, Tehran, Iran. Email: r_dabaghyan@yahoo.com

Hashemi, S. H., Assistant professor, Environmental Science Research Institute, Shahid Beheshti University, Tehran, Iran. Email: h_hashemi@sbu.ac.ir

Ebadi, T., Assistant professor, Department of Civil and Environmental Engineering, Amirkabir University of Technology, Tehran, Iran. Email: tebadi@aut.ac.ir

Maknoon, R., Assistant professor, Department of Civil and Environmental Engineering, Amirkabir University of Technology, Tehran, Iran. Email: maknoon@aut.ac.ir

This article should be referenced as follows:

Dabaghian, M. R.; Hashemi, S. H.; Ebadi, T.; Maknoon, R., (2008). The best available technology for small electroplating plants applying analytical hierarchy process Int. J. Environ. Sci. Tech., 5 (4), 479-484. 